\title{
Weed infestation and yielding of mixtures of blue lupine and spring rye cultivated for green mass
}

\section{Zachwaszczenie i plonowanie mieszanek łubinu wąskolistnego z żytem jarym uprawianych na zieloną masę}

\author{
Anna Płaza*, Barbara Gąsiorowska, Anna Cybulska, Emilia Rzążewska, Rafał Górski
}

\begin{abstract}
Summary
The paper presents the results from years 2009-2011. The objective of the research was to assess the influence of the components in the mixtures of blue lupine and spring rye and the harvest date on weed density and yield. The experiments contained the following groupings: blue lupine (pure sown) $100 \%$, spring rye (pure sown) $100 \%$, blue lupine $75 \%+$ spring rye $25 \%$, blue lupine $50 \%+$ spring rye $50 \%$, blue lupine $25 \%+$ spring rye $75 \%$ and the harvest date: flowering stage of blue lupine, flat green pod stage of blue lupine. The results allowed to conclude that the blue lupine cultivated in pure sown was characterized by higher weed infestation than blue lupine cultivated in the mixtures with spring rye. The mass and number of weed recorded in the mixtures of blue lupine with spring rye that were harvested at the flowering stage of blue lupine were lower than when collected at the flat green pod stage of blue lupine.
\end{abstract}

Key words: mixture; blue lupine; spring rye; weed; yield

\section{Streszczenie}

W pracy przedstawiono wyniki badań z lat 2009-2011 mające na celu określenie wpływu udziału komponentów w mieszance i terminu zbioru na zachwaszczenie i plonowanie mieszanek łubinu wąskolistnego z żytem jarym. W doświadczeniu badano udział komponentów w mieszance: łubin wąskolistny (siew czysty) 100\%, żyto jare (siew czysty) 100\%, łubin wąskolistny $75 \%+$ żyto jare $25 \%$, łubin wąskolistny $50 \%$ + żyto jare $50 \%$, łubin wąskolistny $25 \%$ + żyto jare $75 \%$. Badano także termin zbioru: faza kwitnienia łubinu wąskolistnego, faza płaskiego zielonego strąka łubinu wąskolistnego. Otrzymane wyniki badań pozwalają stwierdzić, iż łubin wąskolistny uprawiany w siewie czystym charakteryzował się większym zachwaszczeniem niż uprawiany w mieszankach z żytem jarym. W mieszankach łubinu wąskolistnego z żytem jarym zebranych w fazie kwitnienia łubinu wąskolistnego odnotowano mniejszą masę i liczbę chwastów niż w mieszankach zebranych w fazie płaskiego zielonego strąka łubinu wąskolistnego.

Słowa kluczowe: mieszanka; łubin wąskolistny; żyto jare; zachwaszczenie; plon

\footnotetext{
Uniwersytet Przyrodniczo-Humanistyczny w Siedlcach

Katedra Agrotechnologii

Prusa 14, 08-110 Siedlce

*corresponding author: plaza@uph.edu.pl
} 


\section{Wstęp / Introduction}

Stopień zachwaszczenia mieszanek bobowato-zbożowych zależy od doboru gatunków, udziału komponentów i terminu zbioru (Staniak i Księżak 2010; Staniak i wsp. 2013; Płaza i wsp. 2017). Mieszanki bobowato-zbożowe znacznie lepiej wykorzystują zasoby gleby dzięki cze$\mathrm{mu}$ w znacznym stopniu ograniczają pobieranie składników pokarmowych przez chwasty (Corre-Hellou i wsp. 2011). Wynika to $\mathrm{z}$ faktu, iż gatunki uprawiane $\mathrm{w}$ mieszankach wypełniają nisze ekologiczne w łanie. Dzięki temu lepsze zwarcie łanu pozwala znacznie skuteczniej konkurować komponentom mieszanek z chwastami (Creamer i wsp. 1996; Buraczyńska 2009; Wojciechowski i wsp. 2013). Spośród roślin bobowatych wysokim plonem świeżej masy wyróżnia się łubin wąskolistny, jednak łatwo ulega zachwaszczeniu. Jedną z dróg ograniczenia zachwaszczenia jest uprawa łubinu wąskolistnego w mieszankach ze zbożami. Wprowadzenie do uprawy żyta jarego, zboża o małych wymaganiach glebowych skłania do podjęcia badań nad oceną jego przydatności jako komponentu mieszanek $\mathrm{z}$ łubinem wąskolistnym. Ponadto żyto jare daje niski plon ziarna, ale wysoki plon zielonej masy. Zasiewy mieszane plonują zazwyczaj wierniej od czystych siewów gatunków, które są komponentami mieszanek (Buraczyńska i Ceglarek 2009; Bojarszczuk i wsp. 2013; Wojciechowski i wsp. 2013). Stąd wyłania się potrzeba prowadzenia tego typu badań.

Celem przeprowadzonych badań było określenie wpływu udziału komponentów i terminu zbioru na zachwaszczenie i plonowanie mieszanek łubinu wąskolistnego z żytem jarym.

\section{Materiały i metody / Materials and methods}

Eksperyment polowy przeprowadzono w latach 20092011 w Rolniczej Stacji Doświadczalnej w Zawadach należącej do Uniwersytetu Przyrodniczo-Humanistycznego w Siedlcach. Badania prowadzono na glebie płowej, o odczynie obojętnym, średniej zasobności w przyswajalny fosfor, potas i magnez. Zawartość próchnicy wynosiła 1,38\%. Doświadczenie polowe założono $\mathrm{w}$ układzie split-blok, w trzech powtórzeniach. Badano dwa czynniki: I - udział komponentów w mieszance: łubin wąskolistny (siew czysty) $100 \%$, żyto jare (siew czysty) $100 \%$, tubin wąskolistny $75 \%+$ żyto jare $25 \%$, hubin wąskolistny $50 \%+$ żyto jare $50 \%$, tubin wąskolistny $25 \%$ + żyto jare $75 \%$, II - termin zbioru: faza kwitnienia łubinu wąskolistnego, faza płaskiego zielonego strąka łubinu wąskolistnego. Szczegółowy skład mieszanek i ilości ich wysiewu przedstawiały się następująco: łubin wąskolistny $200 \mathrm{~kg} / \mathrm{ha}$, żyto jare $200 \mathrm{~kg} / \mathrm{ha}$, łubin wąskolistny $150 \mathrm{~kg} / \mathrm{ha}+$ żyto jare $50 \mathrm{~kg} / \mathrm{ha}$, tubin wąskolistny $100 \mathrm{~kg} / \mathrm{ha}+\dot{z} y$ to jare $100 \mathrm{~kg} / \mathrm{ha}$, łubin wąskolistny $50 \mathrm{~kg} / \mathrm{ha}+$ żyto jare $150 \mathrm{~kg} / \mathrm{ha}$. Jesienią stosowano nawozy fosforowo-potasowe $\mathrm{w}$ dawkach zależnych od zasobności gleby, tj. 35,2 kg/ha P i 99,6 kg/ha K. Wiosną przed siewem nasion stosowano nawożenie azotowe w dawce $30 \mathrm{~kg} / \mathrm{ha} \mathrm{N}$ na wszystkich obiektach, z wyjątkiem łubinu wąskolistnego w siewie czystym. W fazie strzelania w źdźbło dodatkowo zastosowano $50 \mathrm{~kg} / \mathrm{ha} \mathrm{N}$ na żyto jare i $30 \mathrm{~kg} / \mathrm{ha}$ na mieszanki łubinu wąskolistnego z żytem jarym. Siew mieszanek łubinu wąskolistnego (odmiany Zeus) i żyta jarego (odmiany Bojko) przeprowadzono w pierwszej dekadzie kwietnia. Zabiegi pielęgnacyjne polegały na dwukrotnym bronowaniu przed i raz po wschodach roślin broną średnią. Poza tym nie stosowano innych metod zwalczania chwastów. Zbiór roślin przeprowadzono w trzeciej dekadzie czerwca (faza kwitnienia łubinu wąskolistnego) i w pierwszej dekadzie lipca (faza płaskiego zielonego strąka łubinu wąskolistnego). Tuż przed zbiorem mieszanek, $\mathrm{z}$ dwóch losowo wybranych miejsc każdego poletka, wyznaczonych ramką o wymiarach $1,0 \times 0,5 \mathrm{~m}$ pobrano próby chwastów w celu oznaczenia ich liczby oraz świeżej i suchej masy. Natomiast podczas zbioru mieszanek łubinu wąskolistnego z żytem jarym, na każdym poletku określono plon świeżej masy.

Każdą z badanych cech poddano analizie wariancji zgodnie ze schematem układu split-blok. W przypadku istotnych źródeł zmienności dokonano szczegółowego porównania średnich testem Tukeya, przy poziomie istotności $\mathrm{p} \geq 0,05$.

\section{Wyniki i dyskusja / Results and discussion}

Analiza statystyczna wykazała, żeświeża masa chwastów w łanie mieszanek łubinu wąskolistnego z żytem jarym była istotnie różnicowana przez badane czynniki doświadczenia i ich interakcję (tab. 1,2). Największą masę chwastów odnotowano $\mathrm{w}$ łanie łubinu wąskolistnego uprawianego $\mathrm{w}$ siewie czystym. Badania własne są zbieżne z wynikami badań Buraczyńskiej (2009), Bojarszczuk i wsp. (2013), Staniak i wsp. (2013) oraz Wojciechowskiego i wsp. (2013). W badaniach własnych analogicznie, jak u Corre-Hellou i wsp. (2011), Bojarszczuk i wsp. (2013) oraz Płazy i wsp. (2017) dodatek rośliny zbożowej do łubinu wąskolistnego spowodował istotny spadek świeżej i suchej masy chwastów. Natomiast w łanie żyta jarego odnotowano najmniejszą świeżą i suchą masę chwastów. Także Buraczyńska (2009), Bojarszczuk i wsp. (2013) oraz Staniak i wsp. (2014) wskazują na mniejsze zachwaszczenie zbóż uprawianych w siewie czystym. Spośród mieszanek najmniejszą masę chwastów odnotowano w łanie mieszanek łubinu wąskolistnego z żytem jarym o udziale komponentów $75 \%+25 \%$ i $50 \%+50 \%$. Istotnie wyższą masę chwastów odnotowano w łanie mieszanki łubinu wąskolistnego z żytem jarym o udziale komponentów $75 \%+25 \%$. Jednak i w tym przypadku zachwaszczenie łanu było istotnie mniejsze niż łubinu wąskolistnego uprawianego w siewie czystym. Według doniesień literaturowych (Buczek i wsp. 2007; Buraczyńska 2009; Bojarszczuk i wsp. 2013) siewy mieszane mogą istotnie ograniczać zachwaszczenie. Również Szpunar-Krok i wsp. (2009), Staniak i wsp. (2014) oraz Płaza i wsp. (2017) wykazali zmniejszenie zachwasz- 
Tabela 1. Świeża masa chwastów w łanie mieszanek łubinu wąskolistnego z żytem jarym (średnie z lat 2009-2011) $\left[\mathrm{g} / \mathrm{m}^{2}\right]$ Table 1. Fresh green matter of weeds in the blue lupine and spring rye mixtures (average of the years 2009-2011) [g/ $\left./ \mathrm{m}^{2}\right]$

\begin{tabular}{|c|c|c|c|}
\hline \multirow[b]{2}{*}{$\begin{array}{l}\text { Udział komponentów w mieszance } \\
\text { The share of components } \\
\text { in the mixture }\end{array}$} & \multicolumn{2}{|c|}{ Termin zbioru - The harvest date } & \multirow[b]{2}{*}{$\begin{array}{c}\text { Średnie } \\
\text { Means }\end{array}$} \\
\hline & $\begin{array}{c}\text { faza kwitnienia łubinu } \\
\text { wąskolistnego - flowering stage } \\
\text { of blue lupine }\end{array}$ & $\begin{array}{c}\text { faza płaskiego zielonego strąka } \\
\text { łubinu wąskolistnego - flat green } \\
\text { pod stage of blue lupine }\end{array}$ & \\
\hline $\begin{array}{l}\text { Łubin wąskolistny } 100 \% \\
\text { Blue lupine } 100 \%\end{array}$ & 95,3 & 128,0 & 111,7 \\
\hline Żyto jare $100 \%$ - Spring rye $100 \%$ & 36,7 & 44,8 & 40,8 \\
\hline $\begin{array}{l}\text { Eubin wąskolistny } 75 \%+\text { żyto jare } 25 \% \\
\text { Blue lupine } 75 \%+\text { spring rye } 25 \%\end{array}$ & 42,4 & 50,6 & 46,5 \\
\hline $\begin{array}{l}\text { Łubin wąskolistny } 50 \%+\text { żyto jare } 50 \% \\
\text { Blue lupine } 50 \%+\text { spring rye } 50 \%\end{array}$ & 37,2 & 46,4 & 41,8 \\
\hline $\begin{array}{l}\text { Łubin wąskolistny } 25 \%+\text { żyto jare } 75 \% \\
\text { Blue lupine } 25 \%+\text { spring rye } 75 \%\end{array}$ & 35,9 & 43,2 & 39,6 \\
\hline Średnie - Means & 49,5 & 62,6 & - \\
\hline \multicolumn{4}{|l|}{$\operatorname{NIR}(0,05)-\operatorname{LSD}(0.05)$} \\
\hline \multicolumn{3}{|c|}{ Udział komponentów w mieszance - The share of components in the mixture } & 3,6 \\
\hline \multicolumn{3}{|l|}{ Termin zbioru - The harvest date } & 2,0 \\
\hline \multicolumn{3}{|l|}{ Interakcja - Interaction } & 4,4 \\
\hline
\end{tabular}

Tabela 2. Powietrznie sucha masa chwastów w łanie mieszanek łubinu wąskolistnego z żytem jarym (średnie z lat 2009-2011) [g/m²] Table 2. The air-dry matter of weeds in the blue lupine and spring rye mixtures (average of the years 2009-2011) [g/ $\left.\mathrm{m}^{2}\right]$

\begin{tabular}{|c|c|c|c|}
\hline \multirow[b]{2}{*}{$\begin{array}{l}\text { Udział komponentów w mieszance } \\
\text { The share of components } \\
\text { in the mixture }\end{array}$} & \multicolumn{2}{|c|}{ Termin zbioru - The harvest date } & \multirow[b]{2}{*}{$\begin{array}{c}\text { Średnie } \\
\text { Means }\end{array}$} \\
\hline & $\begin{array}{l}\text { faza kwitnienia łubinu } \\
\text { wąskolistnego - flowering stage } \\
\text { of blue lupine }\end{array}$ & $\begin{array}{l}\text { faza płaskiego zielonego strąka } \\
\text { łubinu wąskolistnego - flat green } \\
\text { pod stage of blue lupine }\end{array}$ & \\
\hline $\begin{array}{l}\text { Łubin wąskolistny } 100 \% \\
\text { Blue lupine } 100 \%\end{array}$ & 50,2 & 63,4 & 56,8 \\
\hline Żyto jare $100 \%$ - Spring rye $100 \%$ & 14,9 & 20,0 & 17,4 \\
\hline $\begin{array}{l}\text { Łubin wąskolistny } 75 \%+\text { żyto jare } 25 \% \\
\text { Blue lupine } 75 \%+\text { spring rye } 25 \%\end{array}$ & 22,0 & 29,6 & 25,8 \\
\hline $\begin{array}{l}\text { Łubin wąskolistny } 50 \%+\text { żyto jare } 50 \% \\
\text { Blue lupine } 50 \%+\text { spring rye } 50 \%\end{array}$ & 18,9 & 26,5 & 22,7 \\
\hline $\begin{array}{l}\text { Łubin wąskolistny } 25 \%+\text { żyto jare } 75 \% \\
\text { Blue lupine } 25 \%+\text { spring rye } 75 \%\end{array}$ & 17,2 & 24,8 & 21,0 \\
\hline Średnie - Means & 24,6 & 32,9 & - \\
\hline \multicolumn{3}{|l|}{$\operatorname{NIR}(0,05)-\operatorname{LSD}(0.05)$} & \\
\hline \multicolumn{3}{|c|}{ Udział komponentów w mieszance - The share of components in the mixture } & 2,5 \\
\hline \multicolumn{3}{|l|}{ Termin zbioru - The harvest date } & 1,1 \\
\hline \multicolumn{3}{|l|}{ Interakcja - Interaction } & 3,0 \\
\hline
\end{tabular}

czenia łanów bobowato-zbożowych poprzez konkurencyjność roślin, co jest wynikiem lepszego zwarcia łanu oraz dokładniejszego pokrycia gleby. W badaniach własnych termin zbioru także istotnie różnicował stopień zachwaszczenia łanu mieszanek łubinu wąskolistnego z żytem jarym. Mniejszą masę chwastów odnotowano w łanie mieszanek zbieranych w fazie kwitnienia łubinu wąskolistnego niż w fazie płaskiego zielonego strąka łubinu wąskolistnego, co wynika z mniejszej liczby chwastów. Chwasty zebrane we wcześniejszej fazie rozwojowej mieszanek wytworzyły mniejszą masę. Również Staniak i Księżak (2010), Wojciechowski i wsp. (2013), Bojarszczuk i wsp. (2014), Staniak i wsp. (2014) oraz Płaza i wsp. (2017) odnotowali w swoich badaniach mniejszą masę chwastów w łanie mieszanek bobowato-zbożowych zebranych we wcześniejszych fazach rozwojowych. W omawianym doświadczeniu wykazano interakcję, z której wynika, że najmniejszą świeżą i suchą masę chwastów odnotowano w łanie żyta jarego uprawianego w siewie czystym zebranego w fazie kwitnienia łubinu wąskolistnego, a największą w łanie łubinu wąskolistnego 
uprawianego w siewie czystym zebranego w fazie płaskiego zielonego strąka.

Liczba chwastów była istotnie różnicowana przez badane czynniki doświadczenia i ich współdziałanie (tab. 3). Największą liczbę chwastów odnotowano w łanie łubinu wąskolistnego uprawianego w siewie czystym, a najmniejszą w życie jarym również uprawianym w siewie czystym. Jest to zbieżne z wynikami badań Buraczyńskiej (2009), Wojciechowskiego i wsp. (2013) oraz Płazy i wsp. (2017). W badaniach własnych liczba chwastów w łanie mieszanek łubinu wąskolistnego z żytem jarym była istotnie mniejsza od liczby chwastów w łanie łubinu wąskolistnego uprawianego w siewie czystym. Zmniejszenie udziału łubinu wąskolistnego w mieszance, a zwiększenie żyta jarego powodowało istotny spadek liczby chwastów. Zdaniem Parylak i wsp. (2006), Buczka i wsp. (2007) oraz Staniak i wsp. (2014) siewy mieszane mogą wpływać na redukcję liczby chwastów. W zrealizowanym eksperymencie termin zbioru również istotnie modyfikował liczbę chwastów. Mniejszą liczbę chwastów odnotowano w łanie mieszanek łubinu wąskolistnego z żytem jarym zebranych w fazie kwitnienia łubinu wąskolistnego niż w fazie płaskiego zielonego strąka. Podobną zależność stwierdzili Sobkowicz i PodgórskaLesiak (2007), Bojarszczuk i wsp. (2013), Wojciechowski i wsp. (2013) oraz Płaza i wsp. (2017). Wynika to z faktu, że chwasty w mieszankach zebranych we wcześniejszej fazie rozwojowej charakteryzują się mniejszą masą, a także mniejszą ich liczbą. W badaniach własnych wykazano interakcję badanych czynników, z której wynika, że najmniejszą liczbę chwastów odnotowano w łanie żyta jarego uprawianego w siewie czystym zebranego zarówno w fazie kwitnienia, jak i w fazie płaskiego zielonego strąka łubinu wąskolistnego, a największą w łanie łubinu wąskolistnego uprawianego w siewie czystym, zebranego w fazie płaskiego zielonego strąka.

Analiza statystyczna wykazała istotny wpływ badanych czynników doświadczenia i ich interakcji na plon świeżej masy mieszanek łubinu wąskolistnego z żytem jarym (tab. 4). Największy plon świeżej masy zebrano z mieszanki łubinu wąskolistnego z żytem jarym o udziale komponentów 50\% +50\%. Zdaniem Buraczyńskiej i Ceglarka (2009), Bojarszczuk i wsp. (2013), Wojciechowskiego i wsp. (2013) oraz Staniak i wsp. (2014) zasiewy mieszane plonują lepiej niż siewy czyste, gdyż w większym stopniu wykorzystują zmienne warunki siedliska. W badaniach własnych plon świeżej masy z mieszanek łubinu wąskolistnego z żytem jarym o udziale komponentów $75 \%+25 \%$ i $25 \%+75 \%$ był istotnie niższy niż z mieszanki o udziale komponentów 50\% + 50\%. Plon świeżej masy z żyta jarego kształtował się na zbliżonym poziomie, jak $\mathrm{z}$ mieszanek łubinu wąskolistnego z żytem jarym o udziale komponentów $75 \%+25 \%$ i $25 \%+75 \%$. Termin zbioru także istotnie modyfikował plon świeżej masy mieszanek łubinu wąskolistnego z żytem jarym. Większy plon otrzymano $\mathrm{z}$ mieszanek zebranych $\mathrm{w}$ fazie płaskiego zielonego strąka łubinu wąskolistnego niż w fazie kwitnienia. Również w badaniach Wojciechowskiego i wsp. (2013), Bojarszczuk i wsp. (2014) oraz Płazy i wsp. (2017) mieszanki bobowato-zbożowe zebrane w późniejszej fazie rozwojowej wytworzyły więcej biomasy. W omawianym doświadczeniu wykazano współdziałanie badanych czynników, z którego wynika, że największy plon świeżej masy otrzymano $\mathrm{z}$ mieszanki łubinu wąskolistnego $\mathrm{z}$ żytem jarym o udziale komponentów $50 \%+50 \%$ zebranej w fazie pła-

Tabela 3. Liczba chwastów w łanie mieszanek łubinu wąskolistnego z żytem jarym (średnie z lat 2009-2011) [szt./m²]

Table 3. The number of weeds in the blue lupine and spring rye mixtures (average of the years 2009-2011) [pcs $\left./ \mathrm{m}^{2}\right]$

\begin{tabular}{|c|c|c|c|}
\hline \multirow[b]{2}{*}{$\begin{array}{l}\text { Udział komponentów w mieszance } \\
\text { The share of components } \\
\text { in the mixture }\end{array}$} & \multicolumn{2}{|c|}{ Termin zbioru - The harvest date } & \multirow[b]{2}{*}{$\begin{array}{l}\text { Średnie } \\
\text { Means }\end{array}$} \\
\hline & $\begin{array}{c}\text { faza kwitnienia łubinu } \\
\text { wąskolistnego - flowering stage } \\
\text { of blue lupine }\end{array}$ & $\begin{array}{l}\text { faza płaskiego zielonego strąka } \\
\text { łubinu wąskolistnego - flat green } \\
\text { pod stage of blue lupine }\end{array}$ & \\
\hline $\begin{array}{l}\text { Eubin wąskolistny } 100 \% \\
\text { Blue lupine } 100 \%\end{array}$ & 38 & 44 & 41 \\
\hline Żyto jare $100 \%$ - Spring rye $100 \%$ & 18 & 22 & 20 \\
\hline $\begin{array}{l}\text { Lubin wąskolistny } 75 \%+\text { żyto jare } 25 \% \\
\text { Blue lupine } 75 \%+\text { spring rye } 25 \%\end{array}$ & 33 & 35 & 34 \\
\hline $\begin{array}{l}\text { Łubin wąskolistny } 50 \%+\text { żyto jare } 50 \% \\
\text { Blue lupine } 50 \%+\text { spring rye } 50 \%\end{array}$ & 27 & 30 & 29 \\
\hline $\begin{array}{l}\text { Eubin wąskolistny } 25 \%+\text { żyto jare } 75 \% \\
\text { Blue lupine } 25 \%+\text { spring rye } 75 \%\end{array}$ & 24 & 27 & 26 \\
\hline Średnie - Means & 28 & 32 & - \\
\hline \multicolumn{4}{|l|}{$\operatorname{NIR}(0,05)-\operatorname{LSD}(0.05)$} \\
\hline \multicolumn{3}{|c|}{ Udział komponentów w mieszance - The share of components in the mixture } & 4 \\
\hline \multicolumn{3}{|l|}{ Termin zbioru - The harvest date } & 2 \\
\hline \multicolumn{3}{|l|}{ Interakcja - Interaction } & 6 \\
\hline
\end{tabular}


Tabela 4. Plon świeżej masy mieszanek łubinu wąskolistnego z żytem jarym (średnie z lat 2009-2011) [t/ha]

Table 4. Yield of fresh green matter of the mixtures of blue lupine and spring rye (average of thr years 2009-2011) [t/ha]

\begin{tabular}{|c|c|c|c|}
\hline \multirow[b]{2}{*}{$\begin{array}{l}\text { Udział komponentów w mieszance } \\
\text { The share of components } \\
\text { in the mixture }\end{array}$} & \multicolumn{2}{|c|}{ Termin zbioru - The harvest date } & \multirow[b]{2}{*}{$\begin{array}{c}\text { Średnie } \\
\text { Means }\end{array}$} \\
\hline & $\begin{array}{c}\text { faza kwitnienia łubinu } \\
\text { wąskolistnego - flowering stage } \\
\text { of blue lupine }\end{array}$ & $\begin{array}{l}\text { faza płaskiego zielonego strąka } \\
\text { łubinu wąskolistnego - flat green } \\
\text { pod stage of blue lupine }\end{array}$ & \\
\hline $\begin{array}{l}\text { Łubin wąskolistny } 100 \% \\
\text { Blue lupine } 100 \%\end{array}$ & 23,8 & 36,4 & 30,1 \\
\hline Żyto jare $100 \%$ - Spring rye $100 \%$ & 27,4 & 41,1 & 34,3 \\
\hline $\begin{array}{l}\text { Eubin wąskolistny } 75 \%+\text { żyto jare } 25 \% \\
\text { Blue lupine } 75 \%+\text { spring rye } 25 \%\end{array}$ & 27,6 & 40,2 & 33,9 \\
\hline $\begin{array}{l}\text { Łubin wąskolistny } 50 \%+\text { żyto jare } 50 \% \\
\text { Blue lupine } 50 \%+\text { spring rye } 50 \%\end{array}$ & 34,7 & 48,7 & 41,7 \\
\hline $\begin{array}{l}\text { Łubin wąskolistny } 25 \%+\text { żyto jare } 75 \% \\
\text { Blue lupine } 25 \%+\text { spring rye } 75 \%\end{array}$ & 32,6 & 39,7 & 36,2 \\
\hline Średnie - Means & 29,2 & 41,2 & - \\
\hline \multicolumn{4}{|l|}{$\operatorname{NIR}(0,05)-\operatorname{LSD}(0.05)$} \\
\hline \multicolumn{3}{|c|}{ Udział komponentów w mieszance - The share of components in the mixture } & 2,7 \\
\hline \multicolumn{3}{|l|}{ Termin zbioru - The harvest date } & 1,5 \\
\hline \multicolumn{3}{|l|}{ Interakcja - Interaction } & 3,1 \\
\hline
\end{tabular}

skiego zielonego strąka łubinu wąskolistnego, a najmniejszy z łubinu wąskolistnego uprawianego w siewie czystym zebranego w fazie kwitnienia.

\section{Wnioski / Conclusions}

1. Łubin wąskolistny uprawiany w siewie czystym charakteryzował się większym zachwaszczeniem niż uprawiany w mieszankach z pszenżytem jarym.
2. W mieszankach łubinu wąskolistnego z żytem jarym o udziale komponentów $50 \%+50 \%$ i $25 \%+75 \%$ zebranych w fazie kwitnienia łubinu wąskolistnego odnotowano najmniejszą masę i liczbę chwastów.

3. $\mathrm{Z}$ mieszanek łubinu wąskolistnego $\mathrm{z}$ żytem jarym o udziale komponentów $50 \%+50 \%$ otrzymano największy plon świeżej masy. Plony z pozostałych mieszanek były istotnie niższe, ale wyższe od plonu z łubinu wąskolistnego uprawianego w siewie czystym.

\section{Literatura / References}

Bojarszczuk J., Księżak J., Staniak M. 2014. Evaluation of yielding of oats-pea mixtures cultivated in organic farming. [Ocena plonowania mieszanek grochu z owsem uprawianych w systemie ekologicznym]. Journal of Research and Applications in Agricultural Engineering 59 (3): 12-17.

Bojarszczuk J., Staniak M., Księżak J. 2013. Ocena zachwaszczenia mieszanek grochu z pszenicą jarą uprawianych w systemie ekologicznym. [Weed infestation of mixture of pea with spring wheat cultivated in organic system]. Journal of Research and Applications in Agricultural Engineering 58 (3): 33-40.

Buczek J., Tobiasz-Salach R., Bobrecka-Jamro D. 2007. Ocena plonowania i odchwaszczającego działania jarych mieszanek zbożowych. [Assessment of yielding and weeding effects of mixed spring cereals]. Zeszyty Problemowe Postępów Nauk Rolniczych 516: 11-18.

Buraczyńska D. 2009. Zachwaszczenie mieszanek strączkowo-zbożowych przy zróżnicowanym składzie ilościowo-jakościowym. [Weed infestation of legume-cereal mixtures associated with different quantitative and qualitative composition]. Progress in Plant Protection/ Postępy w Ochronie Roślin 49 (2): 779-783.

Buraczyńska D., Ceglarek F. 2009. Plon i skład chemiczny nasion mieszanek strączkowo-zbożowych. [Yield and chemical composition of legume/cereal mixture seeds]. Fragmenta Agronomica 26 (3): 15-24.

Corre-Hellou G., Dibet A., Hauggaard-Nielsen H., Crozat Y., Gooding M., Ambus P., Dahlmann C., von Fragstein P., Pristeri A., Monti M., Jensen E.S. 2011. The competitive ability of pea-barley intercrops against weeds and the interactions with crop productivity and soil N availability. Field Crops Research 122 (3): 264-272. DOI: 10.1016/j.fcr.2011.04.004.

Creamer N.G., Bennett M.A., Stinner B.R., Cardina J., Regnier E.E. 1996. Mechanism of weed suppression in cover crop-based production systems. HortScience 31 (3): 410-413.

Parylak D., Zawieja J., Jędruszczak M., Stupnicka-Rodzynkiewicz E., Dąbkowska T., Snarska K. 2006. Wykorzystanie zasiewów mieszanych, właściwości odmian lub zjawiska allelopatii w ograniczaniu zachwaszczenia. [Use of the mixed crops, cultivar properties or allelopathy in weed control]. Progess in Plant Protection/Postępy w Ochronie Roślin 46 (1): 33-44. 
Płaza A., Makarewicz A., Gąsiorowska B., Cybulska A., Górski R., Rzążewska E. 2017. Plonowanie a zachwaszczenie mieszanek łubinu wąskolistnego $\mathrm{z}$ owsem uprawianych na zieloną masę. [The yielding and weed infestation of blue lupine mixtures with oat cultivated for green mass]. Progess in Plant Protection 57 (2): 130-134. DOI: 10.14199/ppp-2017-020.

Sobkowicz P., Podgórska-Lesiak M. 2007. Zmiany w zachwaszczeniu zasiewów czystych i mieszanek dwóch odmian grochu z jęczmieniem pod wpływem nawożenia azotowego. [Changes in weed infestation in pure stands and mixtures of two pea cultivars with barley affected by nitrogen fertilization]. Progress in Plant Protection/Postępy w Ochronie Roślin 47 (3): 271-275.

Staniak M., Bojarszczuk J., Księżak J. 2013. Zachwaszczenie zbóż jarych uprawianych w siewie czystym i z wsiewką seradeli (Ornithopus sativa L.) w warunkach gospodarstwa ekologicznego. [Weed infestation of spring cereals cultivated in pure sowing and undersown with serradella (Ornithopus sativa L.) in organic farm]. Woda-Środowisko-Obszary Wiejskie 13 (2): 121-131.

Staniak M., Bojarszczuk J., Księżak J. 2014. The assessment of weed infestation of oats-pea mixtures grown in organic farm. [Ocena zachwaszczenia mieszanek owsa z grochem uprawianych w warunkach gospodarstwa ekologicznego]. Journal of Research and Applications in Agricultural Enginering 59 (4): 83-88.

Staniak M., Księżak J. 2010. Weed infestation of legume-cereal mixtures cultivated in organic farming. [Zachwaszczenie mieszanek strączkowo-zbożowych uprawianych ekologicznie]. Journal of Research and Applications in Agricultural Enginering 55 (4): $121-125$.

Szpunar-Krok E., Bobrecka-Jamro D., Buczek J., Tobiasz-Salach R. 2009. Wpływ poziomu intensywności uprawy na bioróżnorodność flory zachwaszczającej mieszankę wyki siewnej z jęczmieniem jarym. [The effects of cultivation intensity on the biodiversity of weeds occurring in common vetch mixture with spring barley]. Fragmenta Agronomica 26 (4): 170-180.

Wojciechowski W., Kozak M., Białkowska M., Ćwiertniewska M. 2013. Wpływ mieszanek strączkowo-zbożowych na zachwaszczenie łanu. [Effect of legume-cereal mixtures for weed infestation]. Progress in Plant Protection/Postępy w Ochronie Roślin 53 (1): $110-114$. DOI: $10.14199 /$ ppp-2013-126. 